\title{
Estudo do engajamento do cidadão na participação de ações de mandatos eletivos no Legislativo brasileiro: análise do uso de political techs
}

\author{
Jessica Natalia Souza Pavan ${ }^{1}$ \\ LuIS Hernan Contreras PINOChet ${ }^{1}$ \\ GABRIELA DE BRELÀZ ${ }^{1}$ \\ DURVAL LUCAS DOS SANTOS JÚNIOR ${ }^{1}$ \\ DaIElly MElina NASSIF MANTOVANI RIBEIRO ${ }^{2}$ \\ ${ }^{1}$ UnIVERSIDAde FEDERAL de SÃo PAULO (UNIFESP), OSASCO - SP, BRASIL \\ ${ }^{2}$ UNIVERSIDADE DE SÃo PAULO (USP), SÃo PAULO - SP, BRASIL
}

\section{Resumo}

O processo de inovação das tecnologias de informação e comunicação promoveram o desenvolvimento de iniciativas que corroboram maior adesão popular às ações políticas. Diante disso, as political techs surgem como uma forma de inovação do uso da tecnologia para facilitar o acesso às informações e à análise dos candidatos para escolha durante a eleição e como meio de acompanhamento e monitoramento das ações e pautas de governo, auxiliando o processo de participação e engajamento cívico. Esta pesquisa teve por objetivo analisar o engajamento do cidadão, por meio do uso de aplicativos classificados como political techs, na participação em ações de mandatos eletivos no Poder Legislativo brasileiro após as eleições gerais de 2018. A abordagem quantitativa adotou método multivariado de equações de modelagem estrutural, com aplicação de um survey presencial com uma amostra de 467 universitários. Como resultado, a partir das political techs, é proposto um modelo que possibilita a análise por parte dos cidadãos para fiscalizar e participar das decisões sobre os recursos investidos nas políticas e ações públicas, sendo possível, assim, fomentar o engajamento do cidadão.

Palavras-chave: Political tech. Mandato no Legislativo. E-participação. Engajamento.

Study of citizen engagement in the participation of elective mandate actions in the Brazilian Legislature: analysis of the use of political techs

\section{Abstract}

The innovation process of information and communication technologies have led to an increasing engagement of the population in political activities. Political techs emerge as an innovation to facilitate access to information and analysis of candidates during elections. They are used to monitor government actions and agendas, encouraging participation and civic engagement. This research analyzes citizen engagement through political techs adopted in elective mandates in the Brazilian Legislature after the general elections of 2018. The quantitative approach used a multivariate method of structural equation modeling with the application of a face-to-face survey with a sample of 467 university students. As a result, from the political techs, a model is proposed that allows the analysis by the citizens to inspect and participate in the decisions about the resources invested in the public policies and actions, being possible, thus, to foment the citizen's engagement.

Keywords: Political tech. Legislative mandate. E-participation. Engagement.

Estudio del compromiso ciudadano en la participación de las acciones del mandato electivo en el Poder Legislativo brasileño: análisis del uso de political techs

\section{Resumen}

El proceso de innovación de las tecnologías de la información y comunicación impulsaron el desarrollo de iniciativas que corroboran una mayor adhesión popular a las acciones políticas. Por lo tanto, las political techs surgen como una forma de innovación del uso de la tecnología para facilitar el acceso a la información y el análisis de los candidatos para elegir durante la elección y como medio de seguimiento y monitoreo de las acciones y pautas de gobierno, auxiliando el proceso de participación y compromiso cívico. Esta investigación tuvo como objetivo analizar el compromiso ciudadano a través del uso de aplicaciones clasificadas como political techs, en la participación en acciones de mandatos electivos en el Poder Legislativo brasileño después de las elecciones generales de 2018. El enfoque cuantitativo utilizó un método multivariado de ecuaciones de modelado estructural con la aplicación de una survey presencial con una muestra de 467 universitarios. Como resultado, desde las political techs, se propone un modelo que permite el análisis por parte de la ciudadanía para inspeccionar y participar en las decisiones sobre los recursos invertidos en las políticas y acciones públicas, siendo posible, así, fomentar el compromiso ciudadano.

Palabras clave: Political tech. Mandato en el Legislativo. E-participación. Compromiso. 
Estudo do engajamento do cidadão na participação de ações de mandatos eletivos no Legislativo brasileiro: análise do uso de political techs
Jessica Natalia Souza Pavan | Luis Hernan Contreras Pinochet

Gabriela de Brelàz | Durval Lucas dos Santos Júnior Daielly Melina Nassif Mantovani Ribeiro

\section{INTRODUÇÃO}

A interação entre cidadãos, organizações da sociedade civil e governo viabiliza a promoção do engajamento cívico e a ampliação do processo de coprodução em rede. Isso possibilita que se exerça de modo mais efetivo o controle social, sendo um possível caminho para encurtar a distância entre os poderes e ampliar o interesse da população nas ações políticas (YETANO e ROYO, 2016). A articulação entre atores governamentais - nas três esferas: municipal, estadual e federal - e cidadãos deve ocorrer por meio de mecanismos que estimulem a população a se engajar civicamente e fomentem o interesse em participar das decisões e políticas propostas.

O engajamento implica o envolvimento espontâneo do cidadão para acessar dados e informações. Seu sucesso depende da facilidade de acesso às informações e da habilidade ou capacidade dos cidadãos para utilizar o conhecimento compartilhando-o e influenciando pessoas (BIMBER, 2001). A falta de engajamento e de participação dos cidadãos os torna mais distantes, aumenta o desinteresse na política e, consequentemente, diminui o acompanhamento e a participação nas ações e políticas públicas dos governos (FUNG, 2006).

Considerando essa perspectiva e a necessidade de encontrar mecanismos para aproximar o cidadão das ações de governo, entende-se que as tecnologias da informação e comunicação (TICS) podem ser uma forma de estimular a participação e aproximar as pessoas das práticas governamentais (HSU, CHANG e YEN, 2011). O estímulo da participação se torna essencial quando se propõe a pesquisar os fatores que levariam os cidadãos a se engajarem a partir das TICs, por meio de iniciativas que envolvam interação, controle ou participação, e a considerar que, apesar da tecnologia permitir que um maior número de pessoas tenha acesso a informações, isso não significa que seja uma ferramenta totalmente democrática e com pleno acesso às informações e à participação da população.

Diante dos desafios do Poder Legislativo brasileiro e buscando uma forma de estimular a aproximação e a participação dos cidadãos, as TICs podem constituir um mecanismo de interação. Mas, para compreender se as pessoas estão propensas a utilizar novas tecnologias com a finalidade de participar das decisões do Poder Legislativo brasileiro, mostra-se necessário, como exposto em Hirzalla, Zoone e Ridder (2010), obter uma compreensão mais refinada dos elementos que antecedem seu engajamento. Como exemplo, a participação estimulada via uso de aplicativos móveis (apps) oferece maior conveniência e amplia a interatividade e a participação em rede (FUNG, 2006; CHEN, 2015). Diante disso, o que se observa é que o uso da tecnologia voltado à participação tem ganhado cada vez mais espaço na área pública e o surgimento nesse campo de estudo das political techs, startups que disponibilizam iniciativas - por meio do desenvolvimento de soluções baseadas em tecnologia - para acompanhar e acessar informações de candidatos, mandatos e denúncias sobre a atuação parlamentar.

Porém, apesar do avanço nas pesquisas sobre a interação e a troca de informações por meio de mídia móvel, ainda existem poucos estudos que avaliem o comportamento político on-line e a participação social na política - principalmente no que tange ao uso de political techs. Também se mostram necessários estudos que investiguem: a) como o uso dessas tecnologias pode ampliar o acesso à participação política; b) como essas interações ocorrem entre cidadãos, organizações, políticos e governos; e c) como podem produzir efeitos distintos na tomada de decisão (KIM e KLEINSCHMIT, 2012; MARTIN, 2014).

A falta de motivação concedida aos jovens nesse cenário, seja por parte dos familiares, das universidades ou do mercado de trabalho contribui, nesse caso, para que haja uma evasão deles diante dos assuntos políticos, fazendo com que o desinteresse por essa área se torne algo comum. Outro fator contribuinte são as poucas iniciativas de incentivo público-privado para inserir o engajamento dos universitários no contexto político. Seria mais fácil para o universitário que deseja fazer parte da política de seu país se ele encontrasse, com facilidade, iniciativas que o atualizassem e que retesem seu interesse naquilo que ocorre no cenário político. Contudo, há atributos positivos da juventude, associados à inovação e criatividade com o apoio da tecnologia, vistos como agentes portadores de mudança social (SPOSITO e TARÁBOLA, 2016; PAULA e AFONSO, 2018).

Portanto, o objetivo deste artigo é analisar o engajamento do cidadão, por meio do uso de aplicativos classificados como political techs, na participação em ações de mandatos eletivos no Poder Legislativo brasileiro após as eleições gerais de 2018. Após esta introdução, o texto apresenta a seguinte estrutura: a) revisão da literatura (com vistas a apoiar a construção do modelo teórico e das hipóteses testadas na fase empírica do estudo); b) apresentação do método; c) apresentação dos resultados obtidos; e d) conclusões e recomendações. 
Estudo do engajamento do cidadão na participação de ações de mandatos eletivos no Legislativo brasileiro: análise do uso de political techs
Jessica Natalia Souza Pavan | Luis Hernan Contreras Pinochet

Gabriela de Brelàz | Durval Lucas dos Santos Júnior Daielly Melina Nassif Mantovani Ribeiro

\section{REVISÃO DA LITERATURA}

\section{Engajamento do cidadão e participação política}

O engajamento do cidadão pode ser definido como a participação ativa do cidadão na comunidade, a fim de melhorar suas condições (ADLER e GOGGIN, 2005), antecedendo a participação política. A maior parte das atividades de engajamento dos cidadãos pode ser classificada como não política ou semipolítica, ou seja, não diretamente destinada a influenciar parlamentares e chefes do Poder Executivo em assuntos de grande importância para a comunidade. Também existem formas individuais e coletivas de engajamento e de participação, de modo que cada cidadão tem o poder de escolher quando, como e por qual meio se envolver politicamente (GIDDENS, 1991; EKMAN e AMNÅ, 2012).

O engajamento está mais próximo da forma como o indivíduo vai atuar na sociedade, sendo movido pelo sentimento de melhoria coletiva e não apenas pelo interesse próprio. A participação política tem como premissa a vontade do indivíduo influenciar os resultados e as decisões tomadas pelos governantes, podendo estar envolvido em atividades formais ou informais e não estando, necessariamente, vinculado a partidos políticos ou instituições governamentais. O cidadão pode interessar-se em participar formalmente da política escolhendo um candidato no período eleitoral, mas isso não significa que continuará participando apenas por conta desse ato. Da mesma forma, o cidadão que é engajado civicamente pode entender que a participação por meio da escolha de candidatos não acrescenta nada à vida da comunidade, preferindo agir de modo local, sem participar formalmente na política.

Ekman e Amnå (2012) separam a participação em três categorias que devem ser consideradas nos estudos voltados a um melhor entendimento dos cidadãos. A primeira delas é a não participação: o indivíduo não se interessa e não quer se interessar no tema, acreditando que a política não afeta sua vida. A segunda está ligada ao engajamento do cidadão/cívico: o indivíduo se interessa em melhorar a sociedade em que está inserido, entende que a política é algo importante e essencial, mas não necessariamente participa na política. E a terceira diz respeito à participação política formal e ao ativismo, que se caracteriza pela participação ativa dos cidadãos, seja por meio do voto ou pela participação em partidos políticos, organizações e movimentos sociais.

Vale ressaltar que os conceitos de engajamento cívico ainda estão em construção, mas há de considerar-se que é um ponto de partida importante para que se busquem meios para ampliar a participação ativa dos cidadãos na política.

Nesse contexto, a participação e o engajamento on-line têm se tornado importantes mecanismos de discussão e de ativismo. Dessa forma, deve-se considerar as características e os comportamentos observados pelos autores mencionados nesta seção. A incorporação do uso da tecnologia em diversas áreas proporciona modificações significativas no Estado e na forma de buscar o engajamento dos cidadãos na política brasileira.

Diversos exemplos de engajamento cívico - Primavera Árabe, Movimento Occupy nos Estados Unidos da América (EUA), Jornadas de Junho de 2013 no Brasil - são capazes de moldar a dinâmica dos governos e exigir que novos processos sejam incorporados às estruturas de governança (FOTH e BRYNSKOV, 2016). Fung, Gilman e Shkabatur (2013) apresentam seis modelos para a internet e a política, partindo do princípio de que as tecnologias digitais estão transformando a política. Contudo, se por um lado há um grande potencial da internet para aumentar drasticamente a qualidade da governança democrática, por outro, também há indícios - ao examinar os padrões reais de atividade política e expressão nas plataformas digitais - de que essas formas de interação não são capazes de trazer igualdade ou inclusão à política democrática.

Outros estudos demonstram que o engajamento on-line ainda é relativamente baixo, mas há indícios das variáveis que o influenciam. Para Zheng (2015), para entender melhor esse fenômeno, além de explorar fatores que afetam o uso da participação eletrônica dos cidadãos - como características sociodemográficas, uso da internet, percepções políticas, atividades políticas off-line e assim por diante -, é fundamental analisar a funcionalidade de aplicativos de participação eletrônica. Segundo o autor, tais aplicativos estão positivamente associados ao uso da participação eletrônica dos cidadãos e a funcionalidade de alto nível os motiva a incrementar o uso da participação eletrônica. Zolotov, Oliveira e Castelevn (2018), em seus trabalhos sobre engajamento cívico eletrônico, afirmam - com base em 60 estudos - que os melhores preditores usados em modelos de pesquisa para estudar a participação eletrônica são: a) confiança; b) expectativa de esforço; c) utilidade percebida; d) atitude; e) confiança no governo; f) influência social na intenção de usar; g) facilidade percebida de uso; h) utilidade percebida na atitude; e i) intenção de usar. 
Estudo do engajamento do cidadão na participação de ações de mandatos eletivos no Legislativo brasileiro: análise do uso de political techs
Jessica Natalia Souza Pavan | Luis Hernan Contreras Pinochet Gabriela de Brelàz | Durval Lucas dos Santos Júnior Daielly Melina Nassif Mantovani Ribeiro

\section{O avanço das TICs na reformulação do Estado no Brasil}

Todas as iniciativas relacionadas a governo eletrônico, conceito que engloba ações ligadas aos processos e à estrutura necessária para fornecer a interação entre governo e sociedade, baseiam-se em 3 pilares: a) participação; b) colaboração; e c) transparência (DINIZ, BARBOSA, JUNQUEIRA et al., 2009). Esses pilares, em conjunto com as TICs, possibilitam que as ações dos governos possam tornar-se mais eficientes.

Observa-se que o desenvolvimento das TICs no Brasil proporcionou avanços em diversas áreas. Contudo, seu principal uso se deu na melhoria dos processos e da gestão do Poder Executivo, ainda que com pouca ênfase na participação cidadã. Apesar desse cenário, a participação pode ser reconhecida em iniciativas que vão desde a implantação de ouvidores em órgãos públicos e a criação de canais de denúncia até as audiências e as consultas públicas. Avalia-se que as ações de governo eletrônico são fundamentais para um processo de institucionalização e ampliação da democracia digital. No entanto, ter um governo que implementa ações de governo eletrônico, por si só, não significa que o país avance na democracia digital. Ou seja, é primordial que, em conjunto com as ferramentas de governo eletrônico, tenha-se uma política de incentivo à democracia digital.

Normas como a Lei de Responsabilidade Fiscal (Lei Complementar n. 101/2000) e a Lei de Acesso à Informação (Lei n. 12.527/2011) têm nas TICs um suporte ao combate à corrupção, constituindo exemplos de políticas públicas que ampliam a participação cidadã e, principalmente, o controle social.

A e-participação é definida pela Organização das Nações Unidas (ONU) como o processo de envolvimento dos cidadãos, por meio das TICs, na política, na tomada de decisões e na formulação e entrega dos serviços públicos de modo participativo, inclusivo e deliberativo. Todavia, ainda permanece sendo uma prática mais restrita a grupos de pessoas mais jovens, que costumam utilizar as redes para compartilhar informações, expressar apoio a candidatos e discutir política (YAMAMOTO, KUSHIN e FRANCIS, 2014).

Kardan e Sadeghiani (2011) tratam a e-democracia como o uso de TICs e das informações nas instâncias democráticas e no processo político dentro das comunidades. A e-democracia tem por base os processos e as estruturas que permitem a interação entre representantes e representados, ou seja, que possibilitam que governo e cidadão tenham, por meio de mídias eletrônicas, um canal de interação. A principal premissa é a utilização das TICs como ferramentas para ampliar a participação democrática, trazendo o cidadão para o processo político, promovendo accountability e maior interação entre Estado e sociedade, e viabilizando a ampliação do exercício da cidadania.

Para que as TICs sejam, de fato, um mecanismo de ampliação da participação social dentro de mandatos, sejam eles do Poder Legislativo ou do Poder Executivo, é fundamental que haja mudança na forma de pensar a gestão pública. O governo precisa considerar o cidadão parte do processo de decisão, formulação, monitoramento e acompanhamento das ações e políticas públicas (CUNHA e MIRANDA, 2013). Assim como o cidadão precisa compreender que também é seu papel ser um sujeito político e ativo nas tomadas de decisões.

Para Milani (2008), existe uma demanda pela renovação das relações entre governo e sociedade e a necessidade de redesenho do tipo de representação exercida pela tradicional política brasileira. Representação esta que pode ser capitaneada pelo uso das TICs como forma de melhorar essa interação, não importa se a informação vem de uma fonte oficial ou de fake news, pois haverá discussão dos assuntos. Nesse sentido, as mídias sociais têm sido utilizadas de modo mais enfático nas campanhas eleitorais. Tecnologias da Web 2.0 - tais como blogs, sites de redes sociais e sites de compartilhamento de vídeos - são cada vez mais vistas como eficientes ferramentas com poder de mudar a eleição, pois viabilizam o mapeamento dos dados retirados das plataformas e sua integração às táticas de marketing on-line, a fim de influenciar as escolhas dos cidadãos (TOWNER e MUÑOZ, 2016).

A participação on-line pode ser definida como extensão dos conceitos de participação eletrônica (e-participação), referindo-se ao uso extensivo de tecnologias móveis e aplicativos para a ampliação da participação eletrônica. Com a abertura de dados governamentais, uma grande quantidade de aplicativos móveis foi desenvolvida para fornecer aos usuários de smartphones informações sobre cidades ou outras informações de interesse público. Mas é necessário pensar nas formas de mesclar a participação direta e indireta, incluindo as discussões dentro dos movimentos, espaços institucionais e nas ruas (SECCHI, 2009; CHEN, 2015; SECCHI, ALLEGRETTI e TANG, 2016).

Assim, as TICs podem auxiliar o aumento do engajamento cívico, já que permitem que os cidadãos consumam, produzam, distribuam e comentem notícias e informações políticas, criando oportunidades para tentar persuadir politicamente outros indivíduos. As mídias sociais associadas a outros mecanismos de participação podem, portanto, mudar a natureza e o impacto 
Estudo do engajamento do cidadão na participação de ações de mandatos eletivos no Legislativo brasileiro: análise do uso de political techs
Jessica Natalia Souza Pavan | Luis Hernan Contreras Pinochet

Gabriela de Brelàz | Durval Lucas dos Santos Júnior Daielly Melina Nassif Mantovani Ribeiro

de políticas públicas, a opinião de líderes governamentais e, ainda, constituir o primeiro passo para o uso das TICs como ferramenta de participação cidadã (WEEKS, ARDÈVOL-ABREU e ZÚNIGA, 2017).

No entanto, para a promoção de uma participação cidadã efetiva, mostra-se necessário que sejam criados meios para ampliar o engajamento e diminuir os obstáculos a essa participação, seja pela falta de habilidade no uso de TICs, pela falta de interesse no tema ou por falta de conhecimento. A ampliação do acesso a dispositivos móveis influencia positivamente o engajamento democrático, possibilitando, assim, a conexão dos indivíduos de modo rápido, ampliando o sentimento de pertencimento e viabilizando a conexão de cidadãos com afinidades similares. Todavia, é preciso considerar fatores importantes no engajamento de pessoas e movimentos, como os comportamentos pessoais e as atitudes sobre o uso dessas tecnologias (OSTMAN, 2012).

\section{Political techs}

O termo political techs vem de political technology e refere-se a tecnologias desenvolvidas e utilizadas para fins políticos, seja em aplicativos que visam a aumentar a participação dos eleitores ou um software que analisa big data para entender os constituintes. Na era da quarta revolução industrial, vivencia-se uma enxurrada de novas formas de tecnologia política sendo construídas, todas viabilizadas pela internet e por outros avanços tecnológicos.

Os cidadãos precisam entender as political techs para se tornarem mais capazes de participar em decisões sobre seu desenvolvimento, em vez de confiar na boa vontade das empresas ou dos Estados. Em relação ao ressurgimento da democracia, mostra-se necessário entender o que tais tecnologias podem fazer e o que os cidadãos podem fazer. É possível usar as political techs para expandir o escopo da representação política além do que existe atualmente. As political techs podem representar nossas preferências e interesses de modo mais completo e sistemático para os cidadãos. As possibilidades desses modos de engajamento político podem parecer altamente limitadas inicialmente, devido à maciça despolitização da sociedade na era da informação. Porém, a apatia política também não é um resultado necessário do mundo na vida digital.

Nesse sentido, James Susskind (2018), em Future politics, argumenta que a sociedade vive o "crepúsculo da política", pois agora o espaço da política pode estar se fechando devido ao desenvolvimento de TICs mais capazes, integrativas e invasivas.

O monitoramento a partir do uso de political techs é de extrema importância para possibilitar ao cidadão o acompanhamento das despesas e do orçamento público. Assim, o aplicativo, em tempo real, além de aproximar o cidadão do Poder Legislativo, torna-se um facilitador para combater possíveis desvios do erário, e, quiçá, tentativas corruptivas. 0 desenvolvimento de iniciativas locais capazes de promover a inserção dos cidadãos viabilizaria o exercício do controle das despesas públicas, pois o cidadão exerce um papel fundamental, devendo exercitá-lo em todos os momentos, não se restringindo ao momento do voto. $\mathrm{O}$ acompanhamento das propostas de governo, bem como o orçamento público e, sobretudo, a aderência das despesas às políticas públicas reguladas tornariam o cidadão mais presente e controlador do erário que deve ser gasto em programas, projetos e obras públicas, não se permitindo desvios de dinheiro público (KLEIN, 2019).

\section{MODELO TEÓRICO E HIPÓTESES}

A partir de Duane, O’Reilly e Andreev (2014), Kim e Sundar (2014), Venkatesh, Thong e Xu (2012) e Vivek, Beatty, Dalela et al. (2014), criou-se um modelo teórico contendo variáveis latentes específicas para ser aplicado neste estudo. Os construtos relacionados a seguir são os fatores que influenciam o engajamento no uso de aplicativos de political techs pelos cidadãos para participar de mandatos dos eleitos no Poder Legislativo brasileiro.

\section{Facilidade de uso percebida}

A facilidade de uso percebida é o grau em que uma pessoa acredita que o uso de um sistema em particular deve ser livre de esforço, livre de dificuldade. Essa definição segue o conceito de facilidade, ou seja, livre de dificuldade ou grande esforço, sendo que esforço, por sua vez, tem ligação com recursos finitos que devem ser alocados entre diversas atividades que sejam de responsabilidade da pessoa (DAVIS, 1989). Entende-se, neste estudo, a facilidade de uso como a percepção de um baixo esforço para utilizar aplicativos na participação de mandatos, principalmente no que se refere às habilidades técnicas requeridas para o uso e a compreensão do serviço em si. Viehland e Yoong Leong (2010) e Duane, O'Reilly e Andreev (2014) 
Estudo do engajamento do cidadão na participação de ações de mandatos eletivos no Legislativo brasileiro: análise do uso de political techs
Jessica Natalia Souza Pavan | Luis Hernan Contreras Pinochet

Gabriela de Brelàz | Durval Lucas dos Santos Júnior Daielly Melina Nassif Mantovani Ribeiro

abordam em seus estudos o impacto positivo da facilidade de uso percebida sobre a propensão ao consumo. Tomando por base tais estudos, apresentam-se as seguintes hipóteses:

- $\quad$ H1a(+): A facilidade de uso percebida influencia positivamente a confiança na participação de ações de mandatos eletivos no Legislativo brasileiro no uso de political techs.

- $\quad \mathbf{H 1 b}(+)$ : A facilidade de uso percebida influencia positivamente a utilidade percebida na participação de ações de mandatos eletivos no Legislativo brasileiro no uso de political techs.

\section{Utilidade percebida}

A utilidade percebida se refere à noção de um indivíduo sobre o aumento do desempenho de atividades ou a vantagem que um sistema em particular traz para quem o utiliza. Um sistema com alto grau de utilidade percebida é aquele no qual seu usuário enxerga uma relação positiva entre uso e aumento do desempenho (DAVIS, 1989). A experiência do usuário se refere a como o produto é percebido, usado e aprendido. Para influenciá-la positivamente, requer-se um design de produto ou serviço centrado no usuário, principalmente para influenciar aqueles que adotam os produtos mais tardiamente (BROWN e VENKATESH, 2005). Diversas pesquisas propõem que a utilidade percebida tem impacto positivo na propensão ao consumo, destacando-se a de Duane, O'Reilly e Andreev (2014). Assim, construiu-se a seguinte hipótese:

- H2(+): A utilidade percebida influencia positivamente o engajamento na participação de ações de mandatos eletivos no Legislativo brasileiro no uso de political techs.

\section{Inovação pessoal}

A inovação pessoal é definida, segundo Duane O'Reilly e Andreev (2014), como a disposição de um indivíduo para experimentar qualquer nova tecnologia da informação. A inovação pessoal é um ato próprio para cada um dos indivíduos e pode ser considerada o mesmo que a inovação inata, que é parte da personalidade de um indivíduo (IM, KIM e HAN, 2008). Assim, construíram-se as seguintes hipóteses:

- H3a(+): A inovação pessoal influencia positivamente a utilidade percebida na participação de ações de mandatos eletivos no Legislativo brasileiro no uso de political techs.

- $\quad \mathbf{H 3 b}(+)$ : A inovação pessoal influencia positivamente a facilidade de uso percebida na participação de ações de mandatos eletivos no Legislativo brasileiro no uso de political techs.

\section{Influência social}

De acordo com Venkatesh, Thong e Xu (2012), a influência social é evidenciada à medida que os usuários percebem que outras pessoas importantes - como familiares e amigos ou pessoas influentes na mídia ou em determinadas áreas - acreditam que devem usar uma tecnologia específica (BROWN e VENKATESH, 2005). Essas hipóteses são construídas para medir a influência e a intenção comportamental que o indivíduo tem para usar uma tecnologia. Para Weeks, Ardèvol-Abreu e Zúniga (2017), a importância do papel da internet e das mídias sociais na política contrasta com o fato de que parcelas da população se envolvem menos com notícias e informações políticas. Os autores sugerem que esses grupos de pessoas são influenciados por outros grupos que são ativos na busca por informações de caráter político. Assim, construíram-se as seguintes hipóteses:

- H4a(+): A influência social influencia positivamente o engajamento na participação de ações de mandatos eletivos no Legislativo brasileiro no uso de political techs.

- $\quad \mathbf{H 4 b ( + ) : ~ A ~ i n f l u e ̂ n c i a ~ s o c i a l ~ i n f l u e n c i a ~ p o s i t i v a m e n t e ~ a ~ c o n f i a n c ̧ a ~ n a ~ p a r t i c i p a c ̧ a ̃ o ~ e m ~ a c ̧ o ̃ e s ~ d e ~ m a n d a t o s ~ e l e t i v o s ~ n o ~}$ Legislativo brasileiro no uso de political techs.

\section{Confiança}

O sentimento de confiança de um usuário em relação a um serviço on-line é um fator determinante ao considerar seu uso (CHAU, HU, LEE et al., 2006; ROCA, GARCIA e VEGA, 2008). Sanchez-Franco e Rondan-Cataluña (2010) acreditam que a confiança é o antecedente mais importante. Para Duane, O'Reilly e Andreev (2014), quanto maior a confiança e o compromisso ético percebido pelos indivíduos em relação aos fornecedores do serviço on-line, maior será a intenção de utilizar uma plataforma eletrônica. Por conta disso, construiu-se a seguinte hipótese:

- H5(+): A confiança influencia positivamente o engajamento na participação de ações de mandatos eletivos no Legislativo brasileiro no uso de political techs. 
Estudo do engajamento do cidadão na participação de ações de mandatos eletivos no Legislativo brasileiro: análise do uso de political techs
Jessica Natalia Souza Pavan | Luis Hernan Contreras Pinochet Gabriela de Brelàz | Durval Lucas dos Santos Júnior Daielly Melina Nassif Mantovani Ribeiro

\section{Engajamento}

Diante das diferentes abordagens que o conceito engajamento pode apresentar, a definição que mais se aplica é a de estar envolvido, ocupado e interessado em alguma coisa (HIGGINS, 2006). Para Vivek, Beatty, Dalela et al. (2014), o engajamento se liga a valores intrínsecos e extrínsecos, em três dimensões principais que combinam fatores cognitivo-afetivos (entusiasmo) e aspectos comportamentais (participação consciente) e sociais (interação social) do usuário. $O$ autor também aponta que a intensidade de participação e a relação entre usuários e fornecedores de serviços são determinantes para que ocorra o engajamento.

Além disso, o engajamento se associa ao processo de mudança de comportamento, fazendo com que o indivíduo se torne um agente ativo no processo de comunicação.

Utilizou-se o modelo de Duane, O' Reilly, e Andreev (2014) como base central do estudo, com as seguintes adaptações e modificações: a) foram aproveitados os construtos "Facilidade de Uso Percebida", "Utilidade Percebida", "Inovação Pessoal" e "Confiança"; b) em conjunto com esse modelo, também foram empregados os construtos "Influência Social" (VENKATESH, THONG e XU, 2012) e "Engajamento" (VIVEK, BEATTY, DALELA et al., 2014); c) a partir dos 6 construtos utilizados como base para o estudo, foram adaptadas 23 assertivas - excluídas aquelas relacionadas ao construto "Autoeficácia"; e d) perguntas de cunho sociodemográfico foram criadas com objetivo de entender o perfil dos respondentes.

O modelo teórico, suas variáveis latentes e suas respectivas hipóteses, baseadas nas assertivas apresentadas no Apêndice A, resultaram na Figura 1.

Figura 1

Modelo teórico

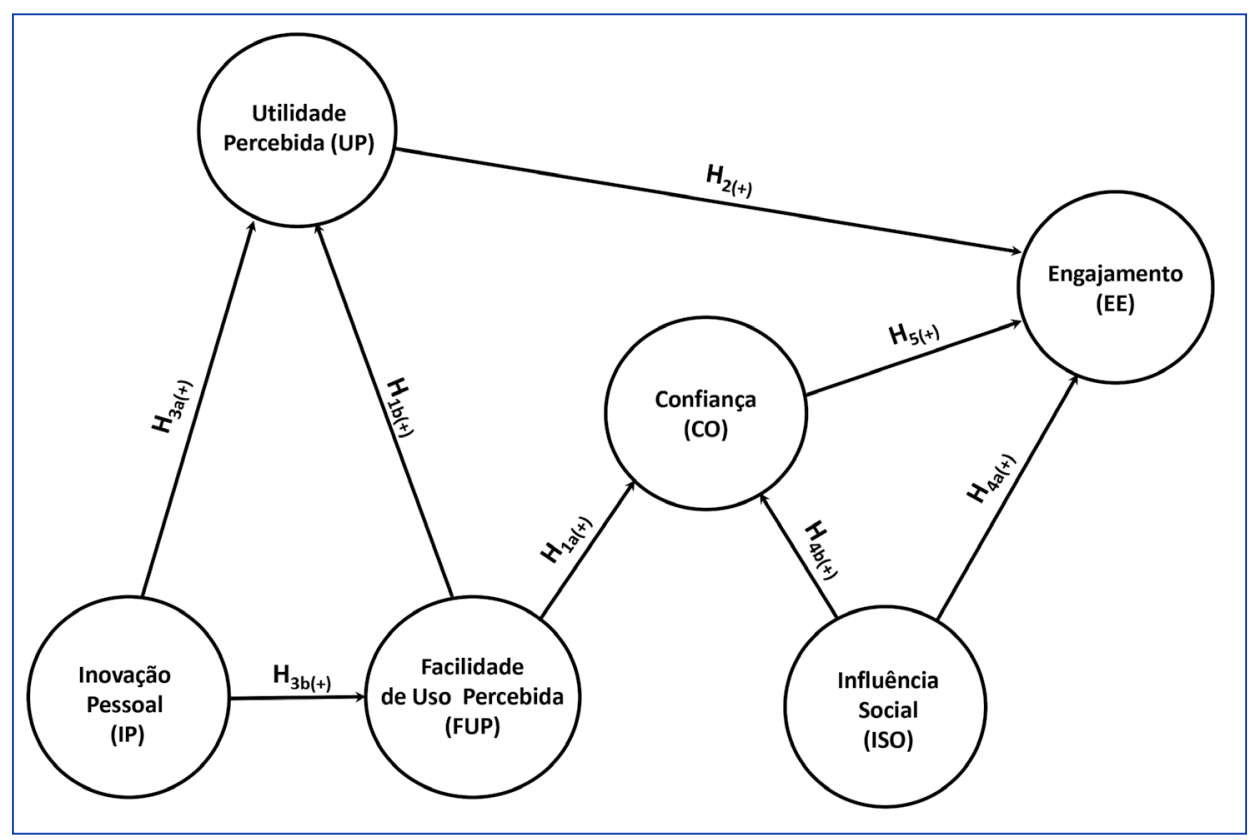

Fonte: Elaborada pelos autores.

\section{MÉTODO}

Neste estudo se realizou uma abordagem quantitativa de natureza descritiva, utilizando a técnica de aplicação de um survey presencial. $O$ instrumento de pesquisa adotou uma escala Likert, variando de 1 - discordo totalmente - a 5 - concordo totalmente - e os questionários foram aplicados de modo presencial, com material impresso. $O$ survey se baseou em aspectos teóricos divididos e foi agrupado em construtos, ou seja, questões que tratam de um mesmo aspecto. A coleta de dados foi realizada em outubro de 2018 , no período pós-eleições. 
Estudo do engajamento do cidadão na participação de ações de mandatos eletivos no Legislativo brasileiro: análise do uso de political techs
Jessica Natalia Souza Pavan | Luis Hernan Contreras Pinochet Gabriela de Brelàz | Durval Lucas dos Santos Júnior Daielly Melina Nassif Mantovani Ribeiro

Os critérios de seleção da amostra foram: a) público jovem; e b) alunos de graduação ou pós-graduação em quatro das principais universidades no Município de São Paulo. Essa escolha se justifica por ser um público com maior acesso às novas tecnologias. Além disso, entende-se que o ambiente universitário está aberto ao debate e ao acesso a novas formas de engajamento e participação. Dessa forma, a escolha do público-alvo visou a identificar a participação e o envolvimento político de universitários (indivíduos que se relacionam com ou pertencem à universidade).

Para a adaptação do modelo ao contexto brasileiro, utilizou-se o processo de tradução reversa e, antes da aplicação do questionário, efetuou-se o pré-teste com 30 indivíduos, para verificar se havia compreensão do instrumento de pesquisa. Considerando que nenhum dos participantes teve dificuldade, iniciou-se a pesquisa com ampliação da amostra. Após a aplicação do teste, foram obtidos 473 questionários no total e 467 observações finais, a partir do processo de purificação da base de dados.

Na etapa da análise descritiva, analisaram-se as informações sobre o perfil demográfico e os dados socioeconômicos dos participantes, bem como questões acerca do conhecimento relativo ao papel do Poder Legislativo e do uso de aplicativos com a finalidade de acompanhar os e participar nos mandatos no Poder Legislativo brasileiro. Para apoiar essa etapa do trabalho foram utilizados os softwares Microsoft Excel e SPSS Statistics.

O método multivariado adotado nesta pesquisa foi a modelagem de equações estruturais, utilizando a metodologia A regressão por mínimos quadrados parciais (partial least squares [PLS]), em que foram mensuradas as correlações entre os construtos e a variável observada, por meio do software SmartPLS, versão 3.2.6. Define-se a modelagem de equações estruturais como sendo o conjunto de técnicas multivariadas que busca a análise simultânea das relações teóricas entre variáveis. Aspectos de regressão múltipla e análise fatorial possibilitam ao pesquisador a verificação de múltiplas relações de dependência e independência entre as variáveis (HAIR, HULT, TOMAS et al., 2014).

\section{ANÁLISE DOS DADOS E RESULTADOS}

Nas eleições gerais de 2018 foram ampliadas as iniciativas para fomentar a participação na escolha de candidatos com perfil mais próximo às conviç̧ões e crenças de cada cidadão. Também houve iniciativas, tanto de assembleias legislativas quanto do Congresso Nacional, para criar aplicativos que viabilizassem o acompanhamento dos mandatos eletivos. Da mesma forma, encontraram-se iniciativas de political techs em organizações sem fins lucrativos e de organizações com fins privados. Diante disso, mapearam-se as principais iniciativas tecnológicas de political techs disponíveis no Google Play Store e na Apple Store, em outubro de 2018. Dentre as principais se encontram as seguintes: a) FiscalizaCidadão; b) MeuVereador; c) NossoMandato; d) CoDeputado; e) Appoie; f) Fala Câmara; g) Aprovômetro; h) Câmara dos Deputados (EDO); i) Poder do Voto; e j) Mudamos+.

\section{Perfil dos respondentes e questões específicas sobre o Legislativo brasileiro}

O perfil dos participantes da pesquisa é apresentado nesta subseção para caracterizar a amostra que forneceu subsídio para a análise da propensão ao uso de aplicativos para participar dos mandatos eletivos do Poder Legislativo. A Tabela 1 detalha as informações sobre sexo, idade, renda familiar e nível educacional.

O público analisado na amostra apresenta grupos masculinos e femininos em percentuais equivalentes e encontra-se na faixa de 17 a 50 anos. Alguns participantes da pesquisa com idade até 50 anos cursam uma nova graduação, enquanto outros têm curso de especialização ou MBA. Portanto, eles também fazem parte do grupo de universitários dentro da amostra. A maior parte da amostra se encontra entre os respondentes com até 25 anos $(76,2 \% / n=356)$ e $84,2 \%$ cursam graduação ( $n=393$ ). No que concerne à renda dos respondentes, o estrato predominante, conforme classificação da Associação Brasileira de Pesquisa (ABEP) foi o $B 2$ : indivíduos com renda de $R \$ 4.852,00$ a $R \$ 9.254,00(30,60 \% / n=143)$.

Dentre os respondentes, $75,6 \%$ dos respondentes ( $n=353$ ) afirmam conhecer o papel do Legislativo, $24,2 \%$ dizem não saber qual é o papel ( $n=113$ ) e 1 respondente deixou a questão em branco. Dos respondentes que dizem conhecer, 54,9\% são homens ( $n=194$ ) e 44,7\% são mulheres ( $n=158$ ); dos que não conhecem, 55,8\% são mulheres ( $n=63$ ) e 44,2\% são homens ( $n=50$ ). Dos que conhecem o papel do Legislativo, $71,8 \%(n=252)$ não acompanharam nenhum mandato do Legislativo e $28,2 \%$ ( $n=99)$ acompanharam algum mandato do Legislativo. 
Estudo do engajamento do cidadão na participação de ações de mandatos eletivos no Legislativo brasileiro: análise do uso de political techs
Jessica Natalia Souza Pavan | Luis Hernan Contreras Pinochet

Gabriela de Brelàz | Durval Lucas dos Santos Júnior Daielly Melina Nassif Mantovani Ribeiro

Na questão sobre os motivos que os levaram a não acompanhar os mandatos, 48,4\% ( $n=160$ ) alegaram desinteresse, 19,6\% $(n=65)$ informaram que seu candidato não foi eleito, $8,48 \%(n=28)$ disseram que o candidato divulgou pouco as informações e $23,3 \%$ ( $n=77)$ mencionaram outros motivos.

Tabela 1

Perfil demográfico dos participantes

\begin{tabular}{|c|c|c|c|}
\hline & & $\mathrm{N}$ & $\%$ \\
\hline \multirow{4}{*}{ Sexo } & Masculino & 244 & 52,2 \\
\hline & Feminino & 222 & 47,5 \\
\hline & Em branco & 1 & 0,2 \\
\hline & Total & 467 & 100 \\
\hline \multirow{4}{*}{$\begin{array}{c}\text { Nível } \\
\text { educacional }\end{array}$} & Cursando graduação & 393 & 84,2 \\
\hline & Graduação concluída & 34 & 7,3 \\
\hline & Cursando pós-graduação & 23 & 4,9 \\
\hline & Pós-graduação concluída & 17 & 3,6 \\
\hline & Total & 467 & 100 \\
\hline \multirow{6}{*}{ Idade } & Até 25 anos & 356 & 76,2 \\
\hline & 26 a 30 anos & 66 & 14,1 \\
\hline & 31 a 35 anos & 27 & 5,7 \\
\hline & 36 a 40 anos & 12 & 2,5 \\
\hline & 41 a 50 anos & 5 & 1,07 \\
\hline & Em branco & 1 & 0,2 \\
\hline \multirow{10}{*}{$\begin{array}{l}\text { Renda } \\
\text { familiar }\end{array}$} & Total & 467 & 100 \\
\hline & Menor $\mathrm{R} \$ 768,00$ & 2 & 0,4 \\
\hline & De $R \$ 768,00$ a $R \$ 1.625,00$ & 18 & 3,9 \\
\hline & De $R \$ 1.625,00$ a $R \$ 2.705,00$ & 62 & 13,3 \\
\hline & $\mathrm{R} \$ 2.705,00$ a $\mathrm{R} \$ 4.852,00$ & 97 & 20,8 \\
\hline & $\mathrm{R} \$ 4.852,00$ a $\mathrm{R} \$ 9.254,00$ & 142 & 30,4 \\
\hline & $R \$ 9.254,00$ a $R \$ 20.888,00$ & 86 & 18,4 \\
\hline & Maior que $\mathrm{R} \$ 20.888,00$ & 46 & 9,9 \\
\hline & Em branco & 14 & 3 \\
\hline & Total & 467 & 100 \\
\hline
\end{tabular}

Fonte: Elaborada pelos autores.

\section{Análise da normalidade}

Nas técnicas de análise multivariada que utilizam variáveis métricas e testes estatísticos, a normalidade multivariada é a condição fundamental de aplicação (HAIR, HULT, TOMAS et al., 2014). Portanto, a normalidade dos dados foi verificada por meio do teste Kolmogorov-Smirnov (K-S) e o respectivo valor $p$ de cada variável. Esse procedimento se mostrou necessário para limitar a possibilidade da utilização de algumas técnicas de análise estatística que tenham como característica a distribuição normal dos dados. Todos os valores $p$ individuais do teste K-S referentes aos indicadores resultaram "muito significativos" $\operatorname{com} p<0,01$. No que concerne às variáveis preditoras relacionadas com a variável latente "Engajamento", pôde-se acomodar a multicolinearidade no modelo. 
Estudo do engajamento do cidadão na participação de ações de mandatos eletivos no Legislativo brasileiro: análise do uso de political techs
Jessica Natalia Souza Pavan | Luis Hernan Contreras Pinochet

Gabriela de Brelàz | Durval Lucas dos Santos Júnior Daielly Melina Nassif Mantovani Ribeiro

\section{Análise do modelo estrutural}

Após a primeira iteração foram apresentados os resultados das cargas fatoriais obtidas pelas variáveis latentes e observou-se que algumas cargas fatoriais indicavam valores abaixo de 0,5. Para o ajustamento de validade convergente (alfa de Cronbach, confiabilidade composta, variância média extraída e coeficientes de determinação) foram excluídas as variáveis EG1, com carga fatorial 0,476 e UP1 com 0,430, que são apresentadas no Apêndice A.

A validade convergente apresentada na Tabela 2 demonstrou a extensão com que a variável latente se correlaciona aos itens escolhidos para medir aquela variável (BAGOZZI, YI e PHILLIPS, 1991).

Os coeficientes de alfa de Cronbach variaram entre 0,543 e 0,833, sendo que valores acima de 0,60 são considerados adequados. Tal resultado mediano indica que o coeficiente é muito sensível ao tamanho da amostra e as escalas foram testadas em um objeto de estudo que não faz parte do cotidiano das pessoas (HELMS, 1999). As confiabilidades compostas obtidas neste estudo variaram entre 0,757 e 0,887 , indicando que os resultados foram satisfatórios nesse sentido.

Para esse modelo, as variâncias médias extraídas (average variances extracted [AVEs]) variaram entre 0,500 e 0,667, o que atinge os critérios de Chin (1998) para a indicação da existência de validade convergente.

O valor $\mathrm{R}^{2}$ mensura a acurácia preditiva do modelo, representando os efeitos combinados das variáveis endógenas sobre as variáveis exógenas. Nesta pesquisa, a variável resposta “Engajamento” foi explicada em 35,8\% no modelo.

De acordo com o critério utilizado para a avaliação da acurácia do modelo ajustado, $\mathrm{Q}^{2}$, todos os construtos foram considerados com acurácia adequada, pois apresentaram valores maiores do que zero, enquanto os construtos "Inovação Pessoal" e "Influência Social" apresentaram valor zero, demonstrando necessidade de aprimoramento em sua acurácia, considerando que se trata de uma temática nova e que necessita de maior aprofundamento. A medida do $\mathrm{f}^{2}$ pode ser classificada usando pontos de corte entre 0,02 e 0,15 como pequenos, de 0,15 até 0,35 como medianos e valores maiores do que 0,35 como grandes (HAIR, HULT, TOMAS et al., 2014). Por fim, a qualidade da medida de ajuste global (goodness of fit [GoF]), no valor de 0,36 (36\%), foi considerado médio para a validade do modelo no PLS.

Tabela 2

Validade convergente

\begin{tabular}{|c|c|c|c|c|c|c|c|}
\hline Variáveis latentes & $\begin{array}{l}\text { Alfa de } \\
\text { Cronbach } \\
>0,60\end{array}$ & $\begin{array}{c}\text { Confiabilidade } \\
\text { composta } \\
>0,70\end{array}$ & $\begin{array}{c}\text { Variância média } \\
\text { extraída (AVE) } \\
>0,50\end{array}$ & $\mathrm{R}^{2}$ & $Q^{2}$ & $f^{2}$ & $\begin{array}{l}\text { Número } \\
\text { de itens }\end{array}$ \\
\hline Confiança & 0,749 & 0,844 & 0,580 & 0,217 & 0,115 & 0,098 & 4 \\
\hline Engajamento & 0,833 & 0,887 & 0,663 & 0,358 & 0,215 & 0,129 & 5 \\
\hline Facilidade de uso percebida & 0,687 & 0,797 & 0,500 & 0,170 & 0,073 & 0,204 & 4 \\
\hline Inovação pessoal & 0,663 & 0,814 & 0,593 & & & & 3 \\
\hline Influência social & 0,543 & 0,757 & 0,513 & & & & 3 \\
\hline Utilidade percebida & 0,753 & 0,857 & 0,667 & 0,142 & 0,086 & 0,054 & 4 \\
\hline
\end{tabular}

Fonte: Elaborada pelos autores.

A validade discriminante avaliou os itens que refletem o fator ou que estão correlacionados com outros fatores. Nesta pesquisa, as variâncias médias extraídas foram superiores ou iguais ao quadrado da correlação entre os fatores, como mostra a Tabela 3 , com o critério de Fornell-Larcker apresentando todas as cargas fatoriais de cada indicador com valores acima de 0,5. 
Estudo do engajamento do cidadão na participação de ações de mandatos eletivos no Legislativo brasileiro: análise do uso de political techs
Jessica Natalia Souza Pavan | Luis Hernan Contreras Pinochet

Gabriela de Brelàz | Durval Lucas dos Santos Júnior Daielly Melina Nassif Mantovani Ribeiro

Tabela 3

Validade discriminante: critério de Fornell-Larcker

\begin{tabular}{lcccccc}
\hline \multicolumn{1}{c}{ Variáveis latentes } & $(1)$ & (2) & (3) & (4) & (5) & (6) \\
\hline (1) Confiança & 0,761 & & & & & \\
(2) Engajamento & 0,400 & 0,814 & & & & \\
(3) Facilidade de uso percebida & 0,375 & 0,369 & 0,707 & & & \\
(4) Inovação pessoal & 0,394 & 0,699 & 0,412 & 0,770 & & \\
(5) Influência social & 0,375 & 0,521 & 0,297 & 0,487 & 0,716 & \\
(6) Utilidade percebida & 0,360 & 0,460 & 0,310 & 0,324 & 0,486 & 0,817 \\
\hline
\end{tabular}

Nota: A diagonal em destaque apresenta as raízes quadradas da AVE.

Fonte: Elaborada pelos autores.

A partir de uma amostra, desenvolvem-se outras amostras compostas de elementos da amostra original e estimam-se os parâmetros do modelo (CHIN, 1998). Diante disso, também se observou a não existência de cargas cruzadas. O modelo proposto nesta pesquisa foi estimado utilizando a técnica bootstrapping, comparando a amostra original com as amostras geradas por essa técnica. Nesse sentido, foram geradas outras 500 amostras e realizou-se o teste $t$ de Student. A análise da significância dos caminhos pode ser verificada a partir dos valores $t$ e das cargas fatoriais das variáveis observáveis. Esses valores são interpretados com base na Tabela 4.

Tabela 4

Análise da significância dos caminhos

\begin{tabular}{|c|c|c|c|c|c|}
\hline Hipóteses & Caminhos & $(\beta)$ & $\begin{array}{l}\text { Bootstrapping } \\
\text { de } 500\end{array}$ & $\begin{array}{c}\text { Erro } \\
\text { padrão }\end{array}$ & Teste $t$ \\
\hline $\mathrm{H} 1 \mathrm{a}(+)$ & $\begin{array}{l}\text { Facilidade de Uso Percebido-> } \\
\text { Confiança }\end{array}$ & 0,289 & 0,293 & 0,048 & 6,002 \\
\hline $\mathrm{H} 1 \mathrm{~b}(+)$ & $\begin{array}{l}\text { Facilidade de Uso Percebido-> } \\
\text { Utilidade Percebida }\end{array}$ & 0,213 & 0,212 & 0,055 & 3,897 \\
\hline $\mathrm{H} 3 \mathrm{a}(+)$ & $\begin{array}{l}\text { Inovação Pessoal-> Utilidade } \\
\text { Percebida }\end{array}$ & 0,236 & 0,239 & 0,053 & 4,421 \\
\hline $\mathrm{H} 3 \mathrm{~b}(+)$ & $\begin{array}{l}\text { Inovação Pessoal-> Facilidade } \\
\text { de Uso Percebido }\end{array}$ & 0,412 & 0,419 & 0,041 & 9,965 \\
\hline $\mathrm{H} 4 \mathrm{a}(+)$ & Influência Social-> Engajamento & 0,340 & 0,340 & 0,046 & 7,397 \\
\hline $\mathrm{H} 4 \mathrm{~b}(+)$ & Influência Social-> Confiança & 0,288 & 0,287 & 0,048 & 5,960 \\
\hline $\mathrm{H} 5(+)$ & Confiança-> Engajamento & 0,191 & 0,192 & 0,046 & 4,151 \\
\hline
\end{tabular}

Nota: Significância - todos os resultados $p<0,001$.

Fonte: Elaborada pelos autores.

A hipótese H3b, com o caminho Inovação Pessoal -> Facilidade de Uso Percebida, teve o maior $\beta(0,412)$. Considerando que a Inovação Pessoal é caracterizada pela abertura do indivíduo a experimentar novas tecnologias e novos serviços (DUANE, O'REILLY e ANDREEV, 2014) e a Facilidade de Uso Percebida é a noção de que o uso de um sistema deve ser livre de grandes dificuldades e esforço para obter os resultados propostos (DAVIS, 1989), a forte relação entre as duas variáveis pode ser explicada pelo fato de que, quando os cidadãos buscam ferramentas como as do estudo, esperam que os aplicativos sejam de fácil interação e entendimento.

O uso dessas ferramentas pode ter um público maior de usuários com características pessoais ligadas à inovação. Ou seja, quem utilizará serão pessoas que já manuseiam aplicativos e entendem que tais mecanismos podem constituir uma forma de ampliação da participação política dos cidadãos no Poder Legislativo. Para isso, a acessibilidade e a interatividade da ferramenta são fundamentais para que o usuário se sinta confortável e confiante para utilizar o aplicativo (ERTIÖ, 2015). 
Estudo do engajamento do cidadão na participação de ações de mandatos eletivos no Legislativo brasileiro: análise do uso de political techs
Jessica Natalia Souza Pavan | Luis Hernan Contreras Pinochet

Gabriela de Brelàz | Durval Lucas dos Santos Júnior Daielly Melina Nassif Mantovani Ribeiro

\section{CONCLUSÃO}

O modelo proposto para este estudo foi desenvolvido com o objetivo de analisar o engajamento do cidadão, por meio do uso de aplicativos classificados como political techs, na participação em ações de mandatos eletivos no Poder Legislativo brasileiro após as eleições gerais de 2018. Como base para a realização da pesquisa foram utilizados construtos adaptados e relacionados ao tema, já que ainda não existem modelos específicos para o estudo na área de gestão pública.

Todas as hipóteses levantadas neste estudo foram suportadas com base nos aspectos teóricos apresentados $(p<0,001)$. Evidenciou-se que há $35,8 \%$ de explicação para o engajamento no uso de aplicativos de political techs, o que é considerado aceitável, mesmo sendo um recurso tecnológico em estágio inicial na sociedade. Isso é um indício de que há interesse por parte dos universitários em adotar uma tecnologia que possa trazer maior informação e visibilidade das atividades administrativas públicas.

O engajamento foi considerado um construto essencial nesta pesquisa para que o cidadão possa utilizar aplicativos e participar dos mandatos com foco no Poder Legislativo. Quanto mais o cidadão se sentir parte do processo e passar a reconhecer que tem voz ativa na interação com o parlamentar, mais engajado ele se torna e, assim, passa a ver sentido na utilização de aplicativos com a finalidade de participar ativamente do processo legislativo.

Diante do exposto, mostra-se fundamental o entendimento da importância, por parte dos cidadãos, de fiscalizar e participar das decisões sobre os recursos investidos nas políticas e ações públicas, sendo possível, a partir desse sentimento de "pertencer", fomentar o engajamento do cidadão. Segundo Serra e Carneiro (2012), o engajamento do cidadão é o controle social na avaliação dos governos de acordo com a atuação em prol do interesse da coletividade. Dessa forma, o engajamento do cidadão requer dos eleitos uma atuação transparente e participativa, que garanta a interação e considere as propostas geradas de modo coletivo na decisão final - no caso do Poder Legislativo, na propositura de projetos de lei e na atuação parlamentar.

As ferramentas de political techs podem auxiliar na interação e participação do cidadão no processo legislativo, já que possibilitam o encaminhamento de sugestões de ideias para os parlamentares (vereadores/deputados/senadores) e permitem a interação e o compartilhamento de informações com outros cidadãos que buscam melhorias. 0 grande desafio, talvez, seja filtrar e avaliar todas as informações e sugestões registradas e fornecer aos participantes, de modo compartilhado, feedbacks sobre a razão de determinada sugestão ter sido acatada ou não, além de garantir que os usuários permaneçam engajados, mantendo um canal aberto com o cidadão com "interlocução ativa" ou, como já mencionado por Higgins (2006), ter a capacidade de manter o indivíduo interessado e envolvido nas iniciativas.

Diante desse desafio, para que os aplicativos sejam, de fato, ferramentas de engajamento social, é fundamental a criação de grupos de trabalho em que se discutam o acompanhamento e as propostas de projetos, bem como sejam expostos subsídios para a tomada de decisão nas votações e proposituras dos eleitos. Porém, para que isso ocorra, é necessário um ambiente favorável à inovação e à abertura para a participação e o controle social.

É necessário que não só os indivíduos, mas também os governantes, compreendam que o Estado deve trabalhar pelo bem comum e com processos participativos que permitam englobar mais "vozes a um mesmo coro", deixando que os interesses públicos se sobreponham aos interesses particulares. Em uma visão otimista do uso da ferramenta, a motivação para sua adoção deveria ser a vontade de participar nas decisões na esperança de mudanças substanciais no cotidiano das pessoas, ampliando o envolvimento entre governantes e governados, possibilitando a mobilização de diversos públicos e buscando englobar todos os gêneros no processo participativo.

Mesmo considerando que a amostra desta pesquisa teve um público específico de universitários, é importante observar que esse tipo de aplicativo também pode ser amplamente utilizado, pois, como analisaram Vivek, Beatty, Dalela et al. (2014), o engajamento está ligado a aspectos comportamentais, sociais e emocionais que, combinados, determinam a intensidade da relação entre o indivíduo e determinada prática. Portanto, o engajamento está diretamente conectado à mudança do comportamento passivo para o comportamento ativo.

Nesse sentido, espera-se que os cidadãos nutram o sentimento de fazer "parte" do processo, gerando ideias criativas e impulsionando as partes interessadas a buscar inovações que venham a ser operacionalizadas futuramente, aproximando cidadão e governo, gerando maior accountability e um sentimento de "responsividade", auxiliando no desenvolvimento da democracia brasileira e tornando os governos mais responsáveis e transparentes. 
Estudo do engajamento do cidadão na participação de ações de mandatos eletivos no Legislativo brasileiro: análise do uso de political techs
Jessica Natalia Souza Pavan | Luis Hernan Contreras Pinochet Gabriela de Brelàz | Durval Lucas dos Santos Júnior Daielly Melina Nassif Mantovani Ribeiro

As características levantadas anteriormente trazem a reflexão de um novo conceito que é utilizado para analisar o engajamento do uso destes aplicativos, que é o engajamento do cidadão, ou seja, o envolvimento e a participação do indivíduo como resposta às condições políticas, econômicas e sociais do país (SABIONI, FERREIRA, BRAGA et al., 2016). O nível de engajamento é influenciado por aspectos demográficos e socioeconômicos.

Como exposto no decorrer do estudo e observado também por Fung (2006), não há uma estratégia padrão para ampliar a participação. Porém, devem-se considerar aspectos importantes para os cidadãos no uso de tecnologia para esse fim, como facilidade de uso, segurança e cooperação com outros meios de participação, aspectos que foram observados na pesquisa apresentada neste artigo. A relação entre o uso da internet e o engajamento cívico surge na medida em que os usuários passam a utilizar aplicativos para se informar, consultam notícias em sites, compartilham informações com seguidores nas redes, por meio das plataformas e dos aplicativos, para encurtar a distância e promover o debate com foco na política brasileira (HILBERT, 2009; OSTMAN, 2012).

A utilização de political techs para participar de mandatos pressupõe que haja um engajamento cívico, considerando que a participação política deve ocorrer antes, durante e depois do pleito eleitoral (EKMAN e AMNÅ, 2012). É necessário, também, que haja engajamento por parte dos parlamentares para que a participação no Poder Legislativo seja mais ampla, democrática e reflita na qualidade das matérias discutidas e aprovadas no Legislativo brasileiro, bem como no interesse e na aproximação do cidadão na atuação política no país.

Boa parte da agenda de pesquisa de participação no Brasil prioriza a relação entre cidadãos e o Poder Executivo. Mesmo que não seja conclusiva, a possível contribuição de tais ferramentas para o adensamento da democracia reside em proporcionar diferentes conhecimentos e ângulos à forma como as campanhas envolvem os eleitores. As political techs contribuem com tecnologias desenvolvidas e usadas para fins políticos, quer seja um aplicativo que visa a aumentar o comparecimento dos eleitores ou um software que analisa grandes volumes de dados para entender os parlamentares.

Com as oportunidades oferecidas pelas political techs, também devem ser observados os riscos. A tecnologia política é adotada para o que pode ser considerado inadequado, por exemplo, os dados pessoais podem ser usados para manipular os cidadãos por meio de campanhas publicitárias direcionadas. Da mesma forma que falsas contas de mídia social, fake news ou tecnologias de political techs mal-intencionadas podem ampliar as visões que não são representativas e expulsar as vozes genuínas.

Por outro lado, as political techs podem transformar positivamente a sociedade e ajudar a lidar com problemas maciços e complexos. Essa tecnologia pode permitir que grupos de pessoas se comuniquem e se organizem com relativa facilidade e conveniência, abrindo debates políticos em conversas anteriormente privadas no domínio público digital. Essas plataformas tecnológicas também podem ajudar novos candidatos a coletar dados e informações em suas campanhas e traçar novas estratégias de comunicação para o engajamento.

Diante desse contexto, as political techs trazem inovações que fomentam novos métodos de criação de ideias e ações e possibilitam a ampliação de canais para a participação e o adensamento da relação entre Estado e sociedade civil. Isso também torna o ambiente institucional mais complexo, especialmente no que se refere aos processos de formulação, coordenação e execução de políticas (PETINELLI, 2013; PIRES e GOMIDE, 2014).

Por fim, o avanço das TICs no Brasil, especificamente quando se observa o fenômeno das political techs, abre uma lacuna no campo de estudo que pode contribuir para a diminuição da crise da democracia, o que é observado mediante a falta de conexão entre o interesse de quem vota e o interesse daquele que é eleito, bem como suas atitudes no exercício do mandato. Esse é o principal fundamento da crise da democracia representativa, que assola vários países, como é o caso do Brasil. 0 controle dos eleitores quanto aos atos praticados pelos representantes pode ser observado a partir da pressão exercida sobre estes e, sobretudo, pela não reeleição dos parlamentares.

Este estudo apresenta indícios de que a participação política instrumentalizada pelas political techs é capaz de tornar exequíveis os objetivos que constituem a ordem democrática brasileira. Desse modo, a utilização do ciberespaço pode assegurar importantes mecanismos de participação e controle social da coisa pública, ampliando os espaços de convivência democrática e permitindo o surgimento de novos atores políticos, o que não cabe somente à ciberdemocracia, mas a toda a sociedade. 
Estudo do engajamento do cidadão na participação de ações de mandatos eletivos no Legislativo brasileiro: análise do uso de political techs
Jessica Natalia Souza Pavan | Luis Hernan Contreras Pinochet Gabriela de Brelàz | Durval Lucas dos Santos Júnior Daielly Melina Nassif Mantovani Ribeiro

\section{Recomendações para a gestão}

A partir dos resultados do estudo, pôde-se refletir sobre sugestões de atuação dos agentes envolvidos (governo, parlamentares eleitos, cidadãos, entidades e empresas parceiras dos governos), para que os aplicativos tenham êxito, e sobre quais são os potenciais benefícios.

A primeira reflexão condiz com o interesse dos governos em ter a participação popular como parte da agenda dos mandatos e buscar ações e projetos que visem à ampliação e à aproximação entre Estado e sociedade, buscando disponibilizar os aplicativos para a população de modo mais claro e com interface de fácil manuseio, divulgando e institucionalizando o uso da tecnologia como forma de participação do cidadão com linguagem mais acessível.

Quando passamos a refletir sobre o papel do cidadão, observamos que, da mesma forma que o governo e os parlamentares, ele também pode contribuir na abertura e participação dos processos e limites de cada esfera de governo. Torna-se necessário, neste ponto, ampliar assuntos relacionados à gestão pública, tão fundamental para o desenvolvimento do país, em ambientes comprometidos com a formação de cidadãos. Não deveria existir "resistência no aprender" dos cidadãos e, por outro lado, são esperadas "explicações mais claras" por parte dos agentes influenciadores na formação da sociedade, sendo que o sucesso ou fracasso dessa prática dialética refletirá diretamente na questão política.

Desse modo, os agentes que conduzem e transmitem as informações devem estar suficientemente preparados para exercer tal atividade com clareza e com o propósito de levar conhecimento e informação à parcela mais vulnerável da população, que - diferentemente do público abordado na pesquisa, em sua maioria jovem e com alto grau de escolaridade e renda representa a maior parte da população brasileira. Como observado por Avritzer (2008), as esferas participativas são compostas não apenas por instituições formais, mas também por agentes sociais com peso na tomada de decisão do cidadão.

Personalidades públicas vêm utilizando esse tipo de tecnologia para engajar e aproximar o cidadão das ações públicas, o que demonstra que as politcal techs vêm ganhando espaço como ferramentas de controle social, monitoramento e acompanhamento das ações de governo, sendo incorporadas por parlamentares eleitos e personalidades públicas que exercem influência sobre os cidadãos. Na mesma perspectiva, tramita na Câmara dos Deputados o Projeto de Lei n. 9.617/2018, que institui a gestão compartilhada, destinada ao acompanhamento orçamentário, financeiro e físico da execução de obras, por grupos de cidadãos organizados em aplicativos agregadores disponíveis na internet, demonstrando, mais uma vez, que o uso de aplicativos constitui objeto de inovação no setor público.

Uma ressalva a essas novas tecnologias de political techs, principalmente aquelas que sugerem os candidatos que mais se assemelham ao perfil de quem está realizando a busca, seria a necessidade do acompanhamento e envolvimento do Tribunal Superior Eleitoral (TSE) como órgão fiscalizador quanto à transparência do método e das metodologias analíticas que os mantém disponíveis em apps ou sites. Nesse sentido, a tecnologia não deve ser utilizada para direcionar o voto sem que o usuário tenha plena consciência de como o aplicativo traz possíveis resultados.

Dessa forma, sugere-se - para futuras pesquisas no campo do uso de aplicativos para ampliar a participação social, seja no Poder Legislativo, Executivo ou Judiciário - a aplicação de modo mais amplo com estratos sociais distintos, principalmente no que concerne à renda, idade e escolaridade, obtendo uma amostra mais heterogênea. 
Estudo do engajamento do cidadão na participação de ações de mandatos eletivos no Legislativo brasileiro: análise do uso de political techs
Jessica Natalia Souza Pavan | Luis Hernan Contreras Pinochet Gabriela de Brelàz | Durval Lucas dos Santos Júnior Daielly Melina Nassif Mantovani Ribeiro

\section{REFERÊNCIAS}

ADLER, R. P.; GOGGIN, J. What do we mean by "civic engagement"? Journal of Transformative Education, v. 3, n. 3, p. 236-253, 2005.

AVRITZER, L. Instituições participativas e desenho institucional: algumas considerações sobre a variação da participação no Brasil democrático. Opinião Pública, v. 14, n. 1, p. 43-64, 2008.

BAGOZZI, R. P.; YI, Y.; PHILLIPS, L. W. Assessing construct validity in organizational research. Administrative Science Quarterly, v. 36, n. 3, p. 421-458, 1991.

BIMBER, B. Information and political engagement in America: the search for effects of information technology at the individual level. Political Research Quarterly, v. 54, n. 1, p. 53-67, 2001.

BROWN, S. A.; VENKATESH, V. Model of adoption of technology in households: a baseline model test and extension incorporating household life cycle. MIS Quarterly: Management Information Systems, v. 29, n. 3, p. 399-426, 2005.

CHAU, P. Y. K. et al. Examining customers' trust in online vendors and their dropout decisions: an empirical study. Electronic Commerce Research and Applications, v. 6, n. 2, p. 171-182, 2006.

CHEN, W. A moveable feast: do mobile media technologies mobilize or normalize cultural participation? Human Communication Research, v. 41, n. 1 , p. 82-101, 2015.

CHIN, W. W. The partial least squares approach for structural equation modeling. In: MARCOULIDES, G. A. (Ed.). Modern methods of business research. Mahwah: Lawrence Erlbaum, 1998. p. 295-336.

CUNHA, M. A. V. C.; MIRANDA, P. R. M. O uso de TIC pelos governos: uma proposta de agenda de pesquisa a partir da produção acadêmica e da prática nacional. Organizações \& Sociedade, v. 20, n. 66, p. 543-566, 2013.

DAVIS, F. D. Perceived usefulness, perceived ease of use, and user acceptance of information technology. MIS Quarterly, v. 13, n. 3, p. 319-339, 1989

DINIZ, E. H. et al. O governo eletrônico no Brasil: perspectiva histórica a partir de um modelo estruturado de análise. Revista de Administração Pública, v. 43, n. 1, p. 23-48, 2009.

DUANE, A.; O'REILLY, P.; ANDREEV, P. Realising M-payments: modelling consumers' willingness to M-pay using smart phones. Behaviour \& Information Technology, v. 33, n. 4, p. 318-334, 2014.

EKMAN, J.; AMNÅ, E. Political participation and civic engagement: towards a new typology. Human Affairs, v. 22, n. 3, p. 283-300, 2012.

ERTIÖ, T. Participatory apps for urban planning: space for improvement. Planning Practice \& Research, v. 30, n. 3, p. 303-321, 2015.

FOTH, M.; BRYNSKOV, M. Participatory action research for civic engagement. In: GORDON, E.; MIHAILIDIS, P. (Ed.). Civic media: technology, design, practice. Cambridge: The MIT Press, 2016. p. $563-580$

FUNG, A. Varieties of participation in complex governance. Public Administration Review, v. 66, n. 1, p. 66-75, 2006.

FUNG, A.; GILMAN, H. R.; SHKABATUR, J. Six models for the internet + politics. International Studies Review, v. 15, p. 30-47, 2013.
GIDDENS, A. Modernity and self-identity: self and society in the late modern age. Stanford: Stanford University Press, 1991.

HAIR, J. F. et al. A primer on partial least squares structural equation modeling (PLS-SEM). Thousand Oaks: Sage, 2014.

HELMS, J. E. Another meta-analysis of the white racial identity scale's Cronbach alphas: implications for validity. Measurement and Evaluation in Counseling and Development, v. 32, n. 3, p. 122-137, 1999.

HIGGINS, T. E. Value from hedonic experience and engagement. Psychological Review, v. 113, n. 3, p. 439-460, 2006.

HILBERT, M. The maturing concept of e-democracy: from e-voting and online consultations to democratic value out of jumbled online chatter. Journal of Information Technology \& Politics, v. 6, n. 2 p. $87-110,2009$

HIRZALLA, F.; ZOONE, L. V.; RIDDER, J. Internet use and political participation: reflections on the mobilization/normalization controversy. The Information Society, v. 27, n. 1, p. 1-15, 2010.

HSU, M. H.; CHANG, C. M.; YEN, C. H. Exploring the antecedents of trust in virtual communities. Behaviour and Information Technology, v. 30, n. 5, p. 587-601, 2011.

IM, I.; KIM, Y.; HAN, H. J. The effects of perceived risk and technology type on users' acceptance of technologies. Information \& Management, v. 45, n. 1, p. 1-9, 2008.

KARDAN A. A.; SADEGHIANI, A. Is e-government a way to e-democracy? A longitudinal study of the Iranian situation. Government Information Quarterly, v. 28, n. 4, p. 466-473, 2011.

KIM, B. J.; KLEINSCHMIT, S. W. A logistic multilevel model for civic engagement and community group impact in the digital age. In: GIL-GARCIA, J. R.; HELBIG, N.; OJO, A. (Ed.). ICEGOV '12. New York: ACM Press, 2012. p. 34-37.

KIM, K. J.; SUNDAR, S. S. Does screen size matter for smartphones? Utilitarian and hedonic effects of screen size on smartphone adoption. Cyberpsychology, Behavior \& Social Networking, v. 17, n. 7, p. 466473, 2014.

KLEIN, A. D. Transparência do orçamento público municipal: desenvolvimento de uma ferramenta (aplicativo) digital capaz de monitorar em tempo real o Legislativo municipal de São Leopoldo (RS). Colóquio: Revista do Desenvolvimento Regional, v. 16, n. 2, p. 207-224, 2019.

MARTIN. J. A. Mobile media and political participation: defining and developing an emerging field. Mobile Media \& Communication, v. 2 , n. 2, p. 173-195, 2014

MILANI, C. R. S. O princípio da participação social na gestão de políticas públicas locais: uma análise de experiências latino-americanas e europeias. Revista de Administração Pública, v. 42, n. 3, p. 551$579,2008$.

OSTMAN, J. Information, expression, participation: how involvement in user-generated content relates to democratic engagement among young people. New Media and Society, v. 14, n. 6, p. 1004-1021, 2012.

PAULA, M. T.; AFONSO, M. L. M. Formação de jovens para a participação política e o exercício da cidadania: uma intercessão entre direito 
Estudo do engajamento do cidadão na participação de ações de mandatos eletivos no Legislativo brasileiro: análise do uso de political techs
Jessica Natalia Souza Pavan | Luis Hernan Contreras Pinochet Gabriela de Brelàz | Durval Lucas dos Santos Júnior Daielly Melina Nassif Mantovani Ribeiro e educação. Revista de Educação do Vale do São Francisco, v. 8, n. 16, p. 56-78, 2018.

PETINELLI, V. Contexto político, natureza da política, organização da sociedade civil e desenho institucional. In: AVRITZER, L.; SOUZA, C. L. (Orgs.). Conferências nacionais. Brasília, DF: Instituto de Pesquisa Econômica Aplicada, 2013. p. 207-242.

PIRES, R. C.; GOMIDE, A. A. Burocracia, democracia e políticas públicas. Brasília, DF: Instituto de Pesquisa Econômica Aplicada, 2014. (Texto para Discussão, n. 1940).

ROCA, J. C.; GARCIA, J. J.; VEGA, J. J. The importance of perceived trust, security and privacy in online trading systems. Information Management \& Computer Security, v. 17, n. 2, p. 96-113, 2008.

SABIONI, M. et al. Contextos (in)adequados para o engajamento cidadão no controle social. Revista de Administração Pública, v. 50, n. 3, p. 477-500, 2016.

SANCHEZ-FRANCO, M.; RONDAN-CATALUÑA, F. J. Connection between customer emotions and relationship quality in online music services. Behaviour \& Information Technology, v. 29, n. 6, p. 633-651, 2010.

SECCHI, L. Modelos organizacionais e reformas da administração pública. Revista de Administração Pública, v. 43, n. 2, p. 247-369, 2009.

SECCHI, M.; ALLEGRETTI, G.; TANG, A. Escalas híbridas de engajamento social: como a integração de tecnologias pode ampliar os processos participativos? In: BALBIM, R. (Org.). Geopolítica das cidades: velhos desafios, novos problemas. Brasília, DF: Instituto de Pesquisa Econômica Aplicada, 2016. p. 213-246.

SERRA, R. C. C.; CARNEIRO, R. Controle social e suas interfaces com os controles interno e externo no Brasil contemporâneo. Espacios Públicos, v. 15, n. 34, p. 43-64, 2012.

SPOSITO, M. P.; TARÁBOLA, F. S. Experiência universitária e afiliação: multiplicidade, tensões e desafios da participação política dos estudantes. Educação \& Sociedade, v. 37, n. 137, p. 1009-1028, 2016.
SUSSKIND, J. Future politics: living together in a world transformed by tech. Oxford: Oxford University Press, 2018.

TOWNER, T. L.; MUÑOZ, C. L. Baby boom or bust? The new media effect on political participation. Journal of Political Marketing, v. 17, n. 1, p. 32-61, 2016.

VENKATESH, V. L.; THONG, J. Y.; XU, X. Consumer acceptance and use of information technology: extending the unified theory of acceptance and use of technology. MIS Quarterly, v. 36, n. 1, p. 157-178, 2012.

VIEHLAND, D.; YOONG LEONG, R. S. Consumer willingness to use and pay for mobile payment services. International Journal of Principles and Applications of Information Science and Technology, v. 3, n. 1, p. 34-46, 2010.

VIVEK, S. D. et al. A generalized multidimensional scale for measuring customer engagement. Journal of Marketing Theory and Practice, v. 22, n. 4, p. 401-420, 2014.

WEEKS, B. E.; ARDÈVOL-ABREU, A.; ZÚNIGA, H. G. Online influence? Social media use, opinion leadership, and political persuasion, International Journal of Public Opinion Research, v. 29, n. 2, p. 214-239, 2017.

YAMAMOTO, M.; KUSHIN, M. J.; DALISAY, F. Social media and mobiles as political mobilization forces for young adults: examining the moderating role of online political expression in political participation. New Media \& Society, v. 17, n. 6, p. 880-898, 2013.

YETANO, A.; ROYO, S. Keeping citizens engaged. Administration \& Society, v. 49, n. 3, p. 394-422, 2016.

ZHENG, Y. Explaining citizens' e-participation usage: functionality of e-participation applications. Administration \& Society, v. 49, n. 3, p. 423-442, 2015.

ZOLOTOV, M. N.; OLIVEIRA, T.; CASTELEVN, S. E-participation adoption models research in the last 17 years: a weight and meta-analytical review. Computers in Human Behavior, v. 81, p. 350-365, 2018. 
Estudo do engajamento do cidadão na participação de ações de mandatos eletivos no Legislativo brasileiro: análise do uso de political techs
Jessica Natalia Souza Pavan | Luis Hernan Contreras Pinochet Gabriela de Brelàz | Durval Lucas dos Santos Júnior Daielly Melina Nassif Mantovani Ribeiro

Jessica Natalia Souza Pavan

ORCID: https://orcid.org/0000-0002-8931-4828

Mestre em Gestão de Políticas e Organizações Públicas pela Escola Paulista de Política, Economia e Negócios (EPPEN) da Universidade Federal de São Paulo (UNIFESP); Bacharel em Administração Pública pela Universidade do Estado de Santa Catarina (UDESC); Assessora Técnica da Secretaria de Governo do Estado de São Paulo, Osasco - SP, Brasil. E-mail: jehpavan@gmail.com

Luis Hernan Contreras Pinochet

ORCID: https://orcid.org/0000-0003-2088-5283

Doutor pela Escola de Administração de Empresas de São Paulo da Fundação Getulio Vargas de São Paulo (FGV EAESP); Professor adjunto do Departamento Acadêmico de Administração da Escola Paulista de Política, Economia e Negócios (EPPEN) da Universidade Federal de São Paulo (UNIFESP), Osasco - SP, Brasil. E-mail: luis.hernan@unifesp.br

Gabriela de Brelàz

ORCID: https://orcid.org/0000-0001-9954-5526

Doutora pela Escola de Administração de Empresas de São Paulo da Fundação Getulio Vargas de São Paulo (FGV EAESP); Professora do Departamento Acadêmico de Administração da Escola Paulista de Política, Economia e Negócios (EPPEN) da Universidade Federal de São Paulo (UNIFESP), Osasco SP, Brasil. E-mail: gabriela.brelaz@unifesp.br

Durval Lucas dos Santos Júnior ORCID: https://orcid.org/0000-0001-7989-5000

Doutor em Administração pela Administração da Faculdade de Economia, Administração e Contabilidade da Universidade de São Paulo (FEA/USP); Professor do Departamento Acadêmico de Administração da Escola Paulista de Política, Economia e Negócios (EPPEN) da Universidade Federal de São Paulo (UNIFESP), Osasco - SP, Brasil. E-mail: durval.lucas@unifesp.br

Daielly Melina Nassif Mantovani Ribeiro

ORCID: https://orcid.org/0000-0001-6320-3268

Doutora em Administração pela Administração da Faculdade de Economia, Administração e Contabilidade da Universidade de São Paulo (FEA/USP); Professora do Departamento de Administração da Faculdade de Economia, Administração e Contabilidade da Universidade de São Paulo (FEA/USP), São Paulo -SP, Brasil. E-mail: daielly@usp.br 
Estudo do engajamento do cidadão na participação de ações de mandatos eletivos no Legislativo brasileiro: análise do uso de political techs
Jessica Natalia Souza Pavan | Luis Hernan Contreras Pinochet

Gabriela de Brelàz | Durval Lucas dos Santos Júnior Daielly Melina Nassif Mantovani Ribeiro

\section{APÊNDICES}

\section{Apêndice A \\ Escala utilizada na pesquisa}

\begin{tabular}{|c|c|c|c|}
\hline Variável Latente & Item & Assertiva & Referência \\
\hline \multirow{4}{*}{$\begin{array}{l}\text { Facilidade de } \\
\text { Uso Percebido } \\
\text { (FUP) }\end{array}$} & FUP1 & $\begin{array}{l}\text { É fácil aprender a operar aplicativos que possibilitem o acompanhamento e a } \\
\text { participação no Legislativo. }\end{array}$ & \multirow[t]{8}{*}{$\begin{array}{l}\text { Kim e Sundar } \\
\text { (2014) }\end{array}$} \\
\hline & FUP2 & $\begin{array}{l}\text { No geral, eu acho fácil de usar aplicativos de acompanhamento de mandatos no } \\
\text { Legislativo. }\end{array}$ & \\
\hline & FUP3 & $\begin{array}{l}\text { O uso de aplicativos de acompanhamento de mandatos no Legislativo não requer } \\
\text { muito conhecimento. }\end{array}$ & \\
\hline & FUP4 & $\begin{array}{l}\text { O uso de aplicativos de acompanhamento de mandatos no Legislativo não requer } \\
\text { muita habilidade técnica. }\end{array}$ & \\
\hline \multirow{4}{*}{$\begin{array}{l}\text { Utilidade } \\
\text { Percebida (UP) }\end{array}$} & UP1 & $\begin{array}{l}\text { O uso de serviços de aplicativos de acompanhamento de mandatos no Legislativo } \\
\text { pode diminuir o tempo necessário para acompanhar o dia a dia do Legislativo. }\end{array}$ & \\
\hline & UP2 & $\begin{array}{l}\text { O uso de aplicativos de acompanhamento de mandatos no Legislativo pode } \\
\text { aumentar meu conhecimento de acordo com a quantidade do meu esforço. }\end{array}$ & \\
\hline & UP3 & $\begin{array}{l}\text { O uso de aplicativos de acompanhamento de mandatos no Legislativo melhora a } \\
\text { eficácia das minhas escolhas futuras. }\end{array}$ & \\
\hline & UP4 & $\begin{array}{l}\text { O uso de aplicativos de acompanhamento de mandatos no Legislativo amplia a } \\
\text { disponibilidade de informações. }\end{array}$ & \\
\hline \multirow{3}{*}{$\begin{array}{l}\text { Inovação } \\
\text { Pessoal (IP) }\end{array}$} & IP1 & $\begin{array}{l}\text { Eu gosto de experimentar os novos aplicativos de acompanhamento de mandatos } \\
\text { no Legislativo. }\end{array}$ & \multirow{8}{*}{$\begin{array}{l}\text { Adaptado de Duane, } \\
\text { O’Reilly e Andreev } \\
\text { (2014) }\end{array}$} \\
\hline & IP2 & $\begin{array}{l}\text { Entre os meus colegas, eu normalmente sou o primeiro a tentar aplicativos de } \\
\text { acompanhamento de mandatos no Legislativo. }\end{array}$ & \\
\hline & IP3 & $\begin{array}{l}\text { Meus colegas levam em consideração minha opinião na hora de usar aplicativos } \\
\text { de acompanhamento de mandatos no Legislativo. }\end{array}$ & \\
\hline \multirow{4}{*}{ Confiança (CO) } & $\mathrm{CO} 1$ & $\begin{array}{l}\text { Eu acredito que os provedores de aplicativos de acompanhamento de mandatos } \\
\text { no Legislativo têm experiência e recursos suficientes para fornecer esses serviços. }\end{array}$ & \\
\hline & $\mathrm{CO} 2$ & $\begin{array}{l}\text { Eu acredito que os provedores de aplicativos de acompanhamento de mandatos } \\
\text { no Legislativo agirão eticamente quanto à captura, retenção, processamento e } \\
\text { gerenciamento das informações oferecidas. }\end{array}$ & \\
\hline & $\mathrm{CO} 3$ & $\begin{array}{l}\text { Eu acredito que os provedores de aplicativos de acompanhamento de mandatos } \\
\text { no Legislativo agem honestamente ao lidar com as informações. }\end{array}$ & \\
\hline & $\mathrm{CO} 4$ & $\begin{array}{l}\text { Eu acredito que todos os prestadores de aplicativos de acompanhamento de } \\
\text { mandatos no Legislativo implementam medidas de segurança adequadas para } \\
\text { proteger os dados informados. }\end{array}$ & \\
\hline \multirow{3}{*}{$\begin{array}{l}\text { Influência } \\
\text { Social (ISO) }\end{array}$} & ISO1 & $\begin{array}{l}\text { A indicação de amigos e familiares me influencia na hora de utilizar aplicativos } \\
\text { de acompanhamento do Legislativo. }\end{array}$ & \\
\hline & ISO2 & $\begin{array}{l}\text { A opinião dos cidadãos e de organizações que utilizam aplicativos de acompanhamento } \\
\text { do legislativo influencia minha decisão em utilizar. }\end{array}$ & \multirow[t]{4}{*}{$\begin{array}{l}\text { Venkatesh, Thong } \\
\text { e Xu (2012) }\end{array}$} \\
\hline & ISO3 & $\begin{array}{l}\text { Pessoas cuja opinião valorizo (especialistas, consultores, entre outros) me motivam } \\
\text { a usar aplicativos para acompanhar o Legislativo Brasileiro. }\end{array}$ & \\
\hline \multirow{5}{*}{$\begin{array}{l}\text { Engajamento } \\
\text { (EM) }\end{array}$} & EN1 & Eu gasto muito do meu tempo livre acompanhando mandatos do Legislativo Brasileiro. & \\
\hline & EN2 & $\begin{array}{l}\text { Eu estou fortemente interessado no uso de aplicativos de acompanhamento de } \\
\text { mandatos do Legislativo Brasileiro. }\end{array}$ & \\
\hline & EN3 & $\begin{array}{l}\text { Qualquer informação ou novidade relacionada a aplicativos de acompanhamento } \\
\text { de mandatos do Legislativo Brasileiro prende a minha atenção. }\end{array}$ & \multirow[t]{3}{*}{$\begin{array}{l}\text { Adaptado de Vivek, } \\
\text { Beatty, Dalela et al. } \\
\text { (2014) }\end{array}$} \\
\hline & EN4 & Gosto de aprender mais sobre acompanhamento de mandatos do Legislativo Brasileiro. & \\
\hline & EN5 & $\begin{array}{l}\text { Eu presto muita atenção a qualquer assunto relacionado ao acompanhamento } \\
\text { de mandatos do Legislativo Brasileiro. }\end{array}$ & \\
\hline
\end{tabular}

Fonte: Elaborado pelos autores. 